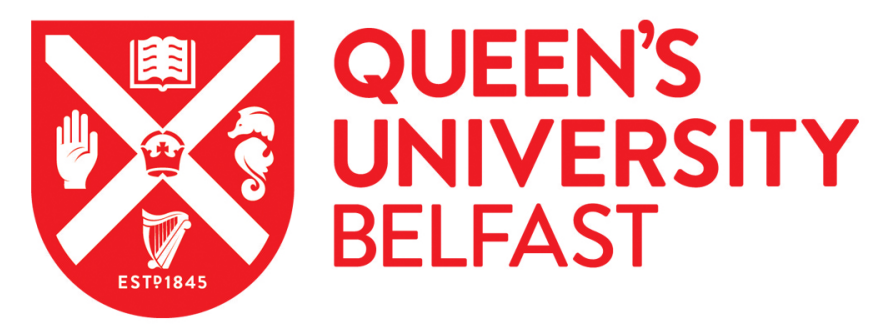

\title{
The effect of teachers trained in a fundamental movement skills programme on children's self-perceptions and motor competence
}

Breslin, G., Murphy, M., McKee, D., Delaney, B., \& Dempster, M. (2012). The effect of teachers trained in a fundamental movement skills programme on children's self-perceptions and motor competence. European Physical Education Review, 18(1), 114-126. https://doi.org/10.1177/1356336X11430657

Published in:

European Physical Education Review

Document Version:

Peer reviewed version

Queen's University Belfast - Research Portal:

Link to publication record in Queen's University Belfast Research Portal

Publisher rights

Copyright $\odot$ 2012, ( SAGE Publications. This work is made available online in accordance with the publisher's policies. Please refer to any applicable terms of use of the publisher.

\section{General rights}

Copyright for the publications made accessible via the Queen's University Belfast Research Portal is retained by the author(s) and / or other copyright owners and it is a condition of accessing these publications that users recognise and abide by the legal requirements associated with these rights.

Take down policy

The Research Portal is Queen's institutional repository that provides access to Queen's research output. Every effort has been made to ensure that content in the Research Portal does not infringe any person's rights, or applicable UK laws. If you discover content in the Research Portal that you believe breaches copyright or violates any law, please contact openaccess@qub.ac.uk. 
'The effect of teachers trained in a fundamental movement skills programme on children's self-perceptions and motor competence'

Breslin, $\mathrm{G}^{1}$, Murphy, M. $\mathrm{H}^{1}$, McKee D. $\mathrm{P}^{2}$, Delaney, B. J ${ }^{2}$, Dempster, $\mathrm{M}^{3}$

${ }^{1}$ Sport and Exercise Sciences Research Institute, University of Ulster, Jordanstown, Belfast, BT37 OQB, UK;

${ }^{2}$ Department of Health and Physical Education, Stranmillis University College Belfast, BT9 5DY.

${ }^{3}$ School of Psychology, Queens University of Belfast. 


\begin{abstract}
Perceived and actual motor competence are hypothesized to have potential links to children and young people's physical activity (PA) levels with a potential consequential link to long term health. In this cross-sectional study Harter's (1985) Competency Motivation-based framework was used to explore whether a group of children taught, during curriculum time, by teachers trained in the Fundamental Movement Skills (FMS) programme, scored higher on self-perception and on core motor competencies when compared to children whose teachers had not been so trained. 177 children aged 7-8 years participated in the study. 107 were taught by FMS-trained teachers (FMS) and the remaining 70 were taught by teachers not trained in the programme (non-FMS). The Harter Self-Perception Profile for Children assessed athletic competence, scholastic competence, global self-worth and social acceptance. Three core components of motor competence (body management, object control and locomotor skills) were assessed via child observation. The FMS group scored higher on all the self-perception domains $(\mathrm{p}<.05)$. Statistically significant differences were found between the schools on all of the motor tasks $(p<.05)$. The relationships between motor performance and self-perception were generally weak and non-significant. Future research in schools and with teachers should explore the FMS programme's effect on children's motor competence via a longitudinal approach.
\end{abstract}

Keywords: health; physical education; physical activity; sport; play; health 


\section{Introduction}

Physical inactivity contributes to 17 non-communicable diseases (Booth, Gordon, Carlson \& Hamilton, 2000), including hypertension, type 2 diabetes, coronary heart disease, stroke, osteoarthritis, cancer and psychological disorders such as depression, distorted body image, eating disorders and low self-esteem (Kaur, Hyder \& Poston, 2003; Schwarzenberg, 2005; Ravens-Sieberer, Redegeld, \& Bullinger, 2001; Patel, Welsh \& Foggs, 2004). However, there is evidence that a substantial proportion of children and young people do not undertake sufficient PA to prevent the onset of risk factors associated with the development of these diseases (Riddoch et al 2009). Thus, significant research effort has focused on the identification of correlates and determinants of PA in children and young people (eg Heitzler et al 2006, Sallis et al 2000). Physical activity during childhood has been shown to be positively associated with gross motor development (Graf, Koch, Kretschmann-Kandel et al, 2004) visual motor coordination (Petrolini, Iughetti \& Bernasconi, 1995) and self-reported athletic coordination (Taylor, Sallis, Dowda, Freedson, Eason, \& Pate, 2002). The effect of motor competence on children's psychosocial development has been recognised in the literature (Stodden, Goodway, Langendorfer, Roberton, Rudisill, Garcia, \& Garcia, 2008). For example, poor coordination has been linked to low self-esteem and poor self-concept (Henderson, May \& Umney, 1989; Losse et al, 1991; Maeland, 1992; Piek, Dworcqan, Barrett, \& Coleman, 2000; Schoemaker \& Kalverboer, 1994), educational underachievement (Gillberg, Gillberg, \& Rasmussen, 1983; O’Dwyer, 1987) and difficulties with peer relations (Schoemaker \& Kalverboer, 1994). Stodden et al (2008) claim that previous research failed to consider the dynamic role that motor skill competence plays in the initiation, maintenance and decline of physical activity and propose that early development of motor skill competence is a primary 
underlying mechanism that promotes engagement in physical activity. There is also growing evidence that levels of physical self-perception and feelings of competence whilst performing motor tasks are factors that may explain why children decide to participate in or avoid physical activity (Barnett, Morgan, Beurden \& Beard, 2008).

Harter's (1987) theory of competence motivation states that, if a child has a positive self-perception and believes that they have mastered the performance of a goal-directed behaviour, they will be more inclined to be motivated to repeat that behaviour. Applying Harter's theoretical framework to motor skill competence would suggest that, if a child is shown how to jump, kick or catch a ball and they learn to perform the skill successfully inducing positive feedback from adults and peers, the child will be likely to have positive self-perception and be motivated to repeat the behaviour. Alternatively, if low self-perception or feelings of incompetence are present when performing the skill, the behaviour will be less likely to be repeated, in an effort to avoid fear of failure and criticism from peers (see also, Crocker, Eklund, Kowalski, 2000). By deciding to avoid motor activities or games that may lead to perceptions of failure or criticism from others, children with low self-perception will reduce their opportunity to participate in play and sporting activities, foregoing the associated health benefits. According to the theory of competence motivation (Harter, 1987), efforts should therefore be made to provide children with opportunities to learn and practice motor skills, including fundamental movement skills, in a supportive instructional environment, wherein competency in performing the skills is actively encouraged and steps are taken to maximise the opportunities for perceived success. The result should be an increase in children's motor competence and self-perception, which may increase the future likelihood of participation in physical activity, sport, play and games. 
The purpose of this study was to investigate, using Harter's (1985) Competency Motivation based framework, whether a group of children taught by teachers who had received a 12 hour Fundamental Movements Skills programme (FMS) (Department of Education, 2001), would score higher on self-perception and core motor competencies (locomotion, body management and object control) when compared to children whose teachers had not been so trained. The aims of the FMS programme are to support the development and integration of the social, emotional and cognitive needs of children through the development of movement competence (FMS resource pack, Western Australian Minister for Education, 2004). To date it is unclear whether a teacher's 12 hour in-service FMS course can influence the development of children's motor competence and self-perceptions. This article will explore via a cross sectional approach the effects of a school based Fundamental Movement Skills (FMS) teacher led intervention programme on primary school children's self-perceptions and motor competence. Gender differences in selfperception and motor competence will also be explored. Implications for conducting further research in this field are discussed.

Method

\section{Recruitment and Participants}

A list of schools whose Primary 2 teachers had received FMS training was provided by Northern Ireland's Education and Library Boards. Ten primary schools were selected and took part in the research; five schools where teachers had received the FMS programme (FMS) and five where they had not (non-FMS). Schools were selected on the basis that the class teacher for 6-7 year olds (Primary 2) had been trained in the programme. Measurements occurred in the October to November period of the academic year following Primary 2, i.e when the children were in Primary 3 
and aged 7-8 years. Schools in each group were matched by the Department for Education, Northern Ireland's (DENI) Research and Statistics Branch based on geographical location (urban or rural), controlled or maintained and socio-economic status (SES). SES, was defined by the uptake of free schools meals in each school and is the measure, expressed as a percentage of the school population, used by the Department of Education in Northern Ireland.

The schools were recruited via a letter sent to the Principal. This was then followed up two days later by a telephone call and, when Principals agreed to take part in the study parental consent forms were distributed for completion. A total of 177 children aged 7-8 years participated in the study. 107 children had had FMStrained teachers while 70 children had not. The lower number of children in the nonFMS group was due to some children not attending school on the day of the research visit or to the absence of parental consent. There was no statistically significant difference between the FMS (54\% male; 52\% high deprivation) and the non-FMS (47\% male; $59 \%$ high deprivation) groups in terms of gender $\left(\chi^{2}=0.871, \mathrm{p}=.351\right.$ ) or in terms of SES $\left(\chi^{2}=0.609, p=.435\right)$, where SES was dichotomised into high deprivation (percentage of pupils receiving free school meals was greater than or equal to $16 \%$ ) and low deprivation (percentage of pupils receiving free school meals was lower than 16\%). This dichotomisation was based on findings published by the Poverty Site which show that schools in areas of low deprivation in Northern Ireland have, on average, $19 \%$ of pupils receiving free school meals (the cut-off point of $16 \%$ used in our analysis was chosen as no school had 19\%). Ethical approval for the study was granted by the Stranmillis University College Research Ethics Committee. 
The FMS programme (Department of Education, Western Australia, 2001) aims to promote proficiency in fundamental movement skills to maximise the health and wellbeing of children through encouraging and facilitating lifelong physical activity. The programme delivered by the primary school teacher during curriculum time is a comprehensive cross curricular resource which seeks to develop three categories of gross motor skill competence; locomotor skills, body management skills and object control skills through a pupil-focused programme. Teachers attend a 12-hour course over two days providing a thorough overview of and insight into the FMS programme. During this time, teachers work with a comprehensive range of resources which enable them to identify and assess children's proficiency and interests in 22 fundamental movement skills, plan and implement appropriate learning experiences and share information about children's skill levels. This is accomplished through theoretical sessions, group work and practical activities. Teachers trained in the FMS programme return to school with a range of physical resources which detail appropriate strategies for delivering the programme and comprehensive details of the key elements of each of the 22 skills.

\section{Assessing Fundamental Movement Skills}

Movement competence was assessed by observing children performing ten motor tasks. The ten tasks were consistent with the tasks identified in the FMS programme, and identified in the Northern Ireland Council for the Curriculum, Examinations and Assessment (NICCEA) guidance for Foundation Stage (Year 1 and Year 2, children aged 4-6) Physical Development and Movement. Seven of the tasks were defined as "discrete tasks" and three as "rich tasks" (see figure 1). The tasks assessed the three core motor skill components of the FMS programme - locomotor, body management and object control skills. The discrete locomotor tasks included the standing broad 
jump and jump-half turn while the discrete object control tasks included the over-arm throw, kicking a ball, trapping a ball and catching a ball. The rich object control tasks were more complex, being designed to assess the ability of children to apply basic skills to more challenging situations, and included discrete tasks embedded in a simple game, "drill", or sequence of movements. The rich tasks included the catch and throw and trapping and kicking a ball. The discrete and rich body management tasks were the balance on one foot and log roll respectively.

To assess motor competence a measurement tool was adapted from existing motor assessment tools that have focused on limb positioning, balance and fluency of movement (see Test of Motor Proficiency, Bruininks, 1978; Movement Assessment Battery for Children, Henderson and Sugden, 1992). Motor competence observations were conducted in the school assembly hall/gymnasium. Children in groups of ten entered the hall and were further split into two groups of five, each group with a gender mix and their own pair of researchers. The discrete and rich tasks were performed individually by each child in response to instructions given by one of the researchers. As each action was performed, the second researcher observed the child and his or her performance for each of the motor skills. The children performed three trials of each motor skill with a five second break between each trial to allow the observer to assess and record all aspects of the movement. The researcher then checked their assessment scores for each skill before moving to the next skill. To avoid inter-observer error the same researcher assessed the same motor skills across children. Researchers were also blind to whether the children were taught by a teacher who was or was not FMS trained. Prior to undertaking the assessment of children's motor skill levels all researchers had completed a minimum of 16 hours training in the procedures and scoring methods employed. 


\section{Assessing Self-Perception}

Children completed a questionnaire addressing four psychological domains from Harter's (1985) Self-Perception Profile for Children. These domains are: athletic competence, scholastic competence, social acceptance and global self-worth. Each domain assesses separate aspects of self-esteem. Athletic and scholastic competence assesses self-perceived competence in these areas, while the social acceptance domain measures self-perceived adequacy. The profile adapts a structured alternative format to reduce social desirability responses (see Harter, 1985). Each domain is assessed by six separate items with a total score summed for each separate domain. The internal consistency reliability ratings of each domain range from .74 to .92 . Children completed the questionnaire in their classrooms following the assessment of their motor skills. The questionnaire was read to the children by their class teachers.

\section{Statistical analysis}

Data was collected in a three-level nested design (individual scores are nested within schools which are nested within groups (FMS and non-FMS). The nature of this hierarchical design needs to be accounted for in the analyses. Therefore, generalised estimating equations (based on an independent working correlation matrix) were used to examine differences between males and females and differences between the ten schools and, therefore, the higher level of differences between the FMS and non-FMS groups. Generalised estimating equations also allow the specification of distributions other than the normal distribution. This facility was particularly useful as several of the distributions under investigation were skewed the catch, balance on one foot and catch/throw motor skills and the Harter global self- 
worth scale. In these cases, the model was based on a gamma distribution (using the inverse of these scores).

Analysis was conducted using PASW Statistics 17.0 software.

\section{Results}

\section{Children's Self-Perceptions}

There were significant differences between the FMS and non-FMS groups on all of the self-perception domains with the FMS group scoring more highly on all the Harter Self-Perception domains (athletic competence, scholastic competence, global selfworth and social acceptance) (see table 1). No gender differences were shown across the Harter Self-Perception domains.

\section{Fundamental Movement Skills}

There were no significant differences in motor skill competence between children who attended schools with FMS-trained teachers when compared to children in a school without such teachers (see table 2). Differences were shown between individual schools on all of the motor tasks wherein the differences between the schools outweighed any differences between the FMS and non-FMS groups on all of the tasks. For example, on the standing broad jump task, there were significant differences between schools within the FMS group and within the non-FMS group but there is no clear pattern of difference between FMS and non-FMS schools overall (see Figure 2). A similar pattern existed for all of the tasks.

Some motor skills were performed to a higher level of competence compared to others. For the discrete tasks, the best performed activity was the balance on one foot, followed by the standing broad jump, catching a ball, kicking a ball, the jump half turn, the over-arm throw and trapping a ball. Of the three rich tasks, performance 
in trapping and kicking a ball and catching a ball and throwing it back, were better than performance of the logroll, which was the least well performed task.

Gender differences were found for the over-arm throw, kicking, trapping, trap/kick and log roll. Males scored more highly than females on all of these skills except the log roll, where girls out-performed boys (see Table 3). The relationships between motor performance and self-perceptions were generally weak and nonsignificant (see Table 4). The relationships between SES and motor performance were also generally weak and non-significant, although the log roll total score was significantly higher among pupils from areas of lower deprivation and the standing broad jump score was significantly higher among pupils from areas of higher deprivation (see Table 5). Furthermore, the Harter scores were significantly higher among pupils from areas of lower deprivation (see Table 5).

\section{Discussion}

The aims of this study were to explore whether there were differences in selfperception and in motor competence between children who were taught by teachers who had received FMS training compared to children taught by teachers who had not been trained in the FMS programme. The study also aimed to look at the relationship between movement competence and self-perception and the effects of gender on both measures.

The findings revealed that children in the FMS group demonstrated significantly higher levels of self-perceptions than the non-FMS groups across four domains of Harter's Self-Perception Profile for Children (1985). Children in the FMS group scored higher in perceptions of their athletic and scholastic competence, higher in social acceptance and higher in global self-worth, which assesses how much they like themselves and are happy with how their lives are organised. These findings may 
suggest that providing a structured movement skills programme during curriculum time to children aged 7-8 years could result in children having a positive view of their athletic and scholarly competence, feeling more accepted by their peers and having higher self-esteem. These findings, when interpreted within Harter's (1987) competence motivation framework, indicate that the opportunity to learn and practice fundamental movement skills in a supportive instructional environment, wherein competency in performing the skills was encouraged by a teacher may have resulted in bringing about this difference in self-perceptions between the FMS and non-FMS groups. The finding that children with FMS-trained teachers reported increased perceptions of their athletic and scholastic competence, higher scores for social acceptance and global self-worth is supportive of previous research that has shown links between perceived competence and physical activity levels in children (Carroll and Loumidis, 2001, Van Wersch, 1997) and in enhancing children's social development (NICCEA, 2007). If a child perceives that they are athletically competent, they are more likely to take part in activities and games involving interaction with other children (Barnett, Morgan, van Beurden \& Beard, 2008). No significant differences between genders were shown across any of the separate selfperception domains or for global self-worth. A non-significant gender effect for scholastic competence and social acceptance supports previous findings but are inconsistent with research showing that males score higher on athletic competence and global self-worth when compared to females (See Eiser, Eiser \& Havermans, 1995).

No significant differences were shown between the FMS and non-FMS groups for motor skill competence, although what did emerge however was a noticeable school effect. That is, instead of the FMS training having a direct effect on the motor 
competence of the FMS group, something other than the FMS intervention may account for the effect. One explanation may have been the children's diverse experiences of play and sport in both the FMS and non-FMS groups. For example, children, whether they attended an FMS school or not, may have previously attended after-school sports clubs, sporting summer schools or had played games with their siblings or peers which could have had a positive influence on motor development. Furthermore the lack of significant motor competence differences between the FMS and non-FMS groups may be explained by the short duration of the influence of the teachers' FMS training. It maybe possible that a 12 hour inservice teachers FMS course, maybe insufficient to bring about significant changes in children's actual motor competence, but is sufficient to bring about changes in self-perceptions of competence. Furthermore the degree to which each teacher embedded the training into their teaching session was not assessed in the current study, so some teachers may have embedded FMS in greater detail into their lessons than other teachers.

There was a gender effect for motor competence where boys outperformed girls on some of the motor tasks. The tasks in which boys performed better were the over-arm throw, kicking and trapping a ball. These findings are supportive of earlier studies showing that girls are less proficient than boys when performing object control skills (Wrotniak, Epstein, Dorn, Jones, Kondilis, 2006; McKenzie, Sallis, Broyles, Zive, Nadar, 2002; van Beurden, Zask, Barnett, Dietrich, 2002; Stratton, et al, 2009). A possible explanation is that object control tasks reflect gender-typed activities wherein boys may have more opportunities to practice activities that involve these motor components than girls. Despite girls and boys having similar perceived athletic competence scores, boys out-performed girls in some motor tasks. Furthermore the relationships between motor performance and self-perceptions were generally weak 
and non-significant. This finding does not support Harter's view that motor competence predicts positive self-perception and our findings may reflect some of the limitations to the present study. Firstly the study's research design was cross-sectional so it was not possible to obtain information on the levels of motor competence of any of the children before the influence of the FMS- and non-FMS-trained teachers. It is possible that the children in the FMS group were lower in motor competence to begin with and the intervention (FMS) brought about a larger increase in movement competency compared to the non-FMS group. To ascertain this information either a pre- and post-test research design or, a longitudinal-type research design would be required to identify the degree of change in motor competence and/or self-perception that actually occurred as a result of the influence of the FMS programme. Furthermore future research could explore the development of a motor competence observation tool suitable for teachers to assess children's motor competence, given the links between motor competence and likelihood to participate in physical activity. A teacher's assessment tool would facilitate early pick up of children with coordination and body management difficulties that could be implemented as a monitoring tool in physical education sessions.

In summary, this study showed that self-perception was higher for children who had been taught by teachers trained in a cross curricular Fundamental Movement Skills programme compared to a group of children who had been taught by teachers who had not received the training. No effect of the FMS programme on motor competence was shown nor was there any strong positive relationship between motor competency and self-perception. Based on the findings, we speculate that children taught by FMS-trained teachers may develop a more positive self-perception with a potential consequence that children who feel better about themselves are more likely 
to participate in PA. However, the relationship between FMS programmes and positive self-perception requires confirmation in either an experimental or longitudinal study. Future research should be directed towards exploring the effect of FMS-trained teachers on promoting children's motor competence, positive selfperception and whether FMS-trained teachers influence children's physical activity levels and/or have an overall positive effect on health.

\section{References}

Barnett, L, M. Morgan, P. J. Van Beurden, E. \& Beard, J, R. (2008). Perceived sports competence mediates the relationship between childhood motor skill proficiency and adolescent physical activity and fitness: a longitudinal assessment. International Journal of behavioural Nutrition and Physical Activity, 5(40) 1-12.

Booth, F.W. Gordon, S.E. Carlson, C.J. Hamilton, M.T. (2000) Waging war on modern chronic diseases: primary prevention through exercise biology. Journal of Applied Physiology, 88(2):774-87.

Bruininks, R. H. (1978) Bruininks-Oseretsky Test of Motor Proficiency Examiner's Manual. Circle Pines, Minn: American Guidance Service.

Carroll, B. and Loumidis, J. (2001) Children's perceived competence and enjoyment in physical education and physical activity outside school. European Physical Education Review, 7(1):24-43

Crocker, P. R. E. Eklund, R. C. Kowalski, K. C. (2000) Children's physical activity and physical self-perceptions. Journal of Sports Science, 18:383-394. 
Department of Education (2001) Fundamental Movement Skills Teachers' Resource, Perth, WA, Education department of Western Australia.

Eiser, C. J. Eiser, R. \& Havermans, T. (1995) The measurement of self-esteem: practical and theoretical considerations. Personality and Individual Differences, 18 (3): 429-432.

Gillberg, I. C. Gillberg, C. \& Rasmussen P. (1983) Three-year follow-up at age 10 of children with minor neurodevelopmental disorders. II. School achievement problems. Developmental Medicine and Child Neurology, 25:566-73.

Graf, C. Koch, B. Kretschmann-Kandel, E. Falkowski, G. Christ, H. Coburger, S. et al. (2004) Correlation between BMI, leisure habits and motor abilities in childhood (CHILT-project). International Journal of Obesity and Related Metabolic Disorders, 28:22-26.

Harter, S. (1985) Manual for the self-perception profile for children. Denver: University of Denver.

Harter, S. (1987). The determinants and meditational role of global self-worth in children. In N. Eisenberg (Ed.), Contemporary issues in developmental psychology (pp. 219-242). New York: Wiley.

Henderson, S. May, D. \& Umney, M. (1989) An exploratory study of goal-setting behaviours, self-concept and locus of control in children with movement difficulties. European Journal of Special Needs Education, 4: 1-15. 
Henderson, S. \& Sugden, D. (1992) Movement Assessment Battery for Children: manual. San Antonio, TX, Psychological Corporation.

Kaur, H. Hyder, ., L. Poston, W. S. C. (2003) Childhood overweight: An expanding problem. Treatments in Endocrinology, 2 (6):375-388.

Losse, A. Henderson, S. E. Elliman, D. Hall, D. Knight, E, \& Jongmans, M. (1991)

Clumsiness in children - Do they grow out of it? A 10 year follow-up study.

Developmental Medicine and Child Neurology, 33: 55-68.

Maeland, A. F. (1992) Handwriting and perceptual motor skills in clumsy, dysgraphic, and 'normal' children. Perceptual and Motor Skills, 75:1207-1217.

McKenzie, T. L. Sallis, J. F. Broyles, S. L.. Zive, M. M.,.\& Nader, P. R. (2002)

Childhood Movement Skills: Predictors of Physical Activity in Anglo American and Mexican American Adolescents? Research Quarterly in Exercise and Sport, 73(3):238-244.

Northern Ireland Council for the Curriculum Examinations and Assessment (2007)

Northern Ireland Curriculum. Key Stages $1 \& 2$ curriculum support and implementation box , Belfast NICCEA

O’Dwyer, S. (1987). Characteristics of highly and poorly co-ordinated children. The Irish Journal of Psychology, 8(1): 1-8. 
Patel, P. H. Welsh, C. \& Foggs, M. B. (2004) Improved asthma outcomes using a coordinated care approach in large medical group. Disease Management, 7(2):102111.

Petrolini, N. Iughetti, L. Bernasconi, S. (1995) Difficulty in visual motor coordination as a possible cause of sedentary behaviour in obese children. International Journal of Obesity and Related Metabolic Disorders, 19:928.

Piek, J. P. Dworkan, M. Barrett, N. C. \& Coleman, R. (2000) Determinants of selfworth in children with and without developmental coordination disorder. International Journal of Disability, Development and Education, 47:259-272.

Ravens-Sieberer, U. Redegeld, M. \& Bullinger, M. (2001) Quality of life after inpatient rehabilitation in children with obesity. International Journal of Obesity and Related Metabolic Disorders, 25(1):63-65.

Riddoch, C. J. Mattocks, C. Deere, K. Saunders, J. Kirkby, J. Tilling, K. Leary, S, D. S. Blair, S. N. \& Ness, A. R. (2007). Objective measurement of levels and patterns of physical activity, Archives of Diseases in Childhood, 92:963-969.

Sallis, J.F. Prochaska, J.J. Taylor, W.C. (2000) A review of correlates of physical activity of children and adolescents. Medicine \& Science in Sports \& Exercise, 32(5): $-963-975$. 
Schoemaker, M. M. \& Kalverboer, A. F. (1994) Social and affective problems of children who are clumsy: How early do they begin? Adapted Physical Activity Quarterly, 11:130-140.

Stodden, D. F. Goodway, J. D. Langendorfer, S. J. Roberton, M. A. Rudisill, M. E. Garcia, C. \& Garcia, L. E. (2008) A Developmental Perspective on the Role of Motor Skill Competence in Physical Activity: An Emergent Relationship. Quest, 60:290306.

Stratton, G. McWhannell, N. Foweather, L. Henaghan, J. Graves, L. Ridgers, N. D. \& Hepples, J. (2009) The A-CLASS Project Research Findings: Executive Summary. Liverpool: Sportslinx.

Taylor, W. Sallis, J. Dowda, M. Freedson, P. Eason, K. Pate, R. (2002) Activity patterns and correlates among youth: differences by weight status. Pediatric Exercise Science, $14: 418-431$.

Van Beurden, E. Zask, A. Barnett, L.M. \& Dietrich, U.C. (2002) Fundamental movement skills - How do primary school children perform? The 'Move It Groove It' program in rural Australia. Journal of Science Medicine in Sport, 5(3):244-252.

Van Wersch, A. (1997) Individual differences and intrinsic motivation for sports participation. In Kremer, J. Trew, K. Ogle, S. (eds) Young people's involvement in sport, pp 55-77, London, Routledge. 
Wrotniak, B.H. Epstein, L.H. Dorn, J.M. Jones, K.E. Kondilis, V.A.(2006) The

Relationship between Motor Proficiency and Physical Activity in Children.

Pediatrics, 118(6):1758-1765. 


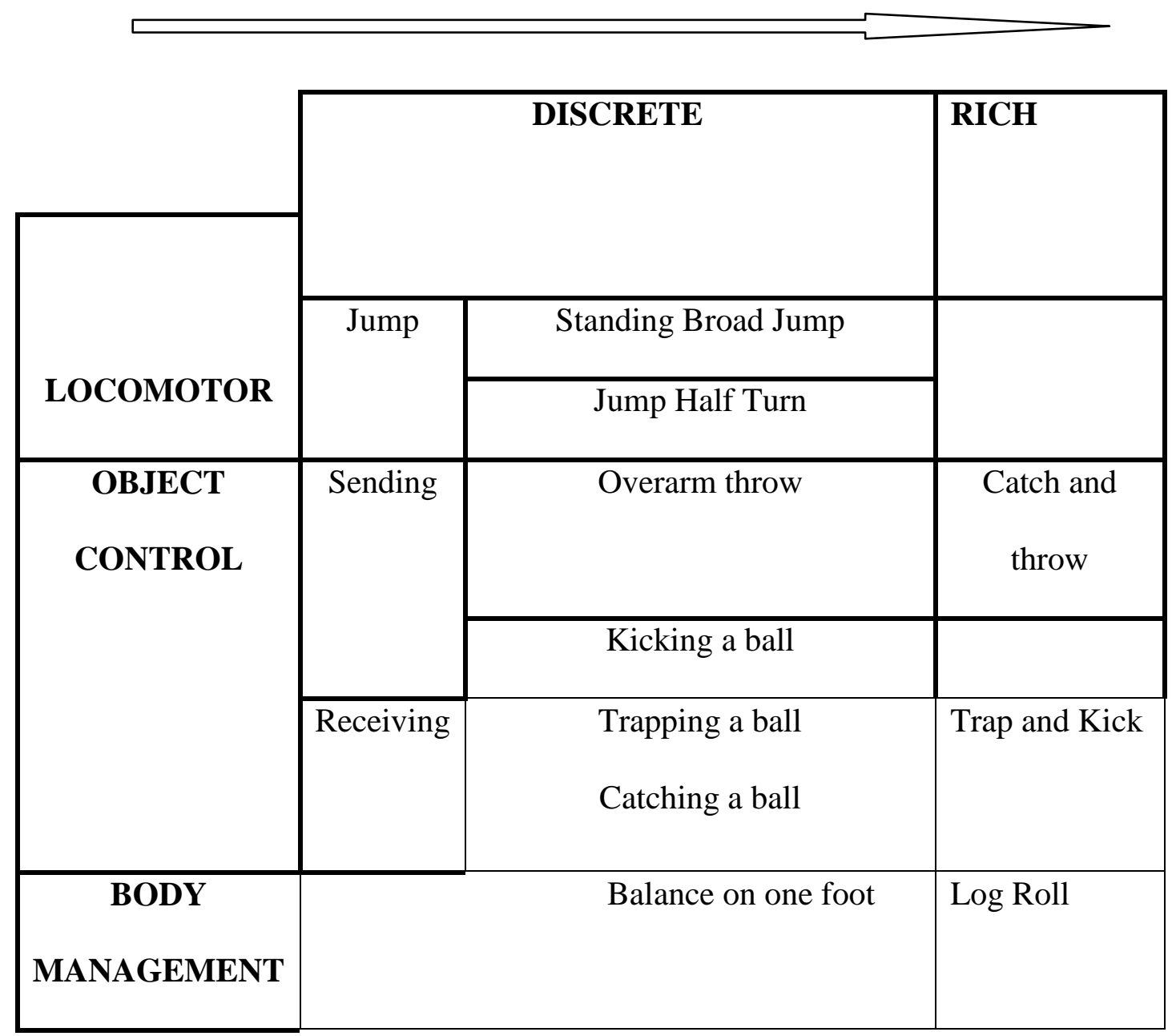

Figure 1: Ten discrete and rich tasks representing body management, object control and locomotor skills 


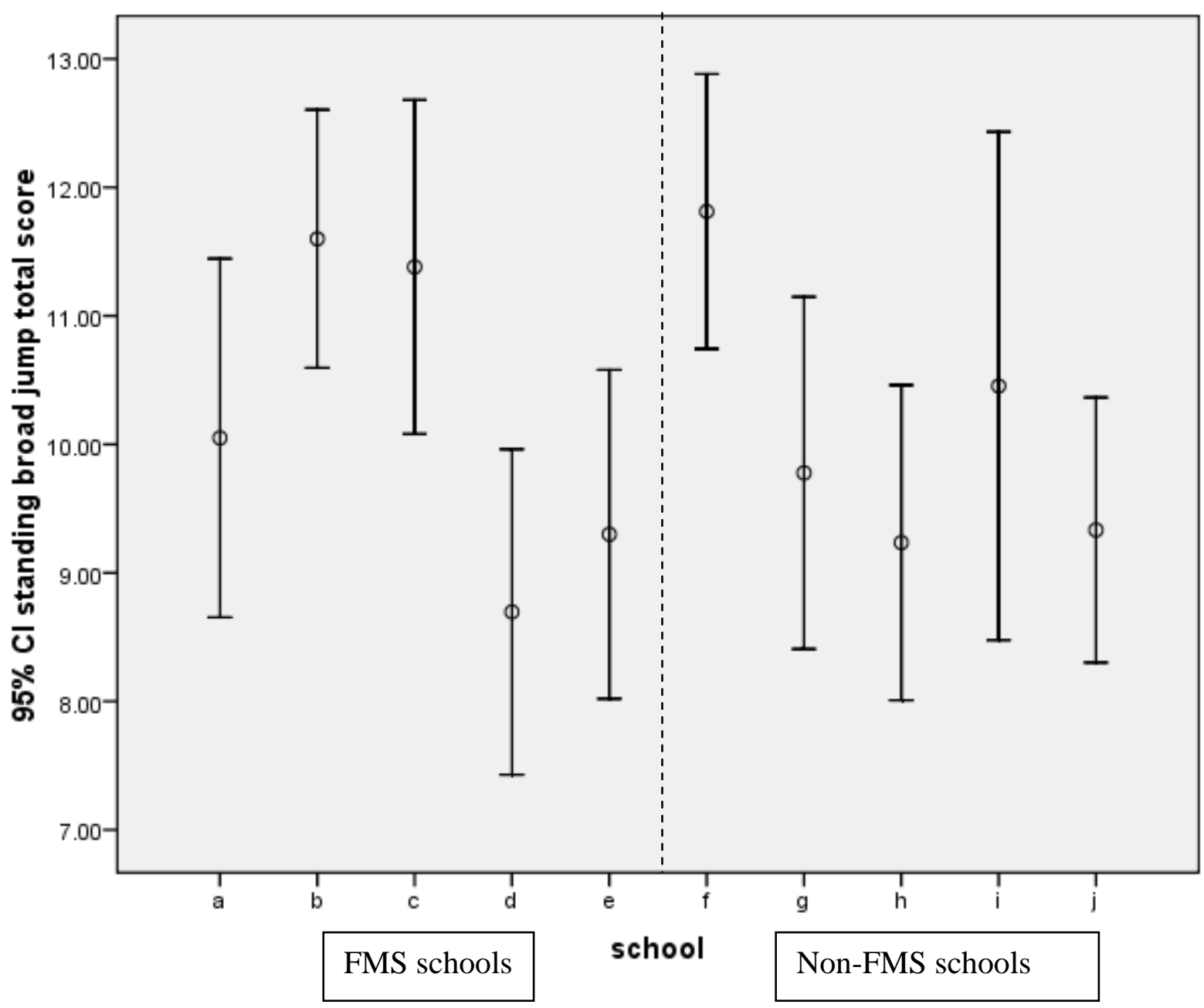

Figure 2: Mean and 95\% confidence interval for total scores on the standing broad jump task for each school 
Table 1: Mean and standard deviation of scores on the Harter scale divided by group

\begin{tabular}{llcccc}
\hline & Groups & Mean & S D & N & p \\
Harter scholastic & Non-FMS & 2.6 & .6 & 47 & $<.001$ \\
competence & FMS & 3.0 & .6 & 71 & \\
Harter social & Non-FMS & 2.6 & .5 & 47 & .002 \\
acceptance & FMS & 2.9 & .7 & 71 & \\
Harter athletic & Non-FMS & 2.7 & .5 & 47 & .001 \\
competence & FMS & 3.1 & .7 & 71 & \\
Harter global & Non-FMS & 2.9 & .6 & 47 & .006 \\
self- worth & FMS & 3.3 & .7 & 71 & \\
\hline
\end{tabular}


Table 2: Mean and standard deviation of total scores on each task divided by group

\begin{tabular}{|c|c|c|c|c|c|}
\hline & Groups & Mean & $\mathrm{SD}$ & $\mathrm{N}$ & $\mathrm{p}$ \\
\hline Standing & Non-FMS & 10.1 & 2.6 & 70 & .621 \\
\hline broad jump & FMS & 10.3 & 2.9 & 107 & \\
\hline Jump half & Non-FMS & 9.5 & 2.6 & 70 & .793 \\
\hline turn & FMS & 9.3 & 2.5 & 107 & \\
\hline Overarm & Non-FMS & 7.5 & 3.3 & 70 & .635 \\
\hline throw & FMS & 7.1 & 3.8 & 107 & \\
\hline \multirow[t]{2}{*}{ Kicking } & Non-FMS & 7.1 & 2.5 & 70 & .286 \\
\hline & FMS & 7.5 & 3.1 & 107 & \\
\hline \multirow[t]{2}{*}{ Catch } & Non-FMS & 6.9 & 2.1 & 70 & .174 \\
\hline & FMS & 7.3 & 2.2 & 107 & \\
\hline \multirow[t]{2}{*}{ Trapping } & non-FMS & 5.3 & 2.3 & 70 & .707 \\
\hline & FMS & 5.1 & 2.5 & 107 & \\
\hline Balance on & Non-FMS & 5.6 & 2.2 & 70 & .864 \\
\hline one foot & FMS & 5.5 & 2.1 & 107 & \\
\hline \multirow[t]{2}{*}{ Catch/throw } & Non-FMS & 3.6 & 1.9 & 70 & .264 \\
\hline & FMS & 4.2 & 1.8 & 107 & \\
\hline \multirow[t]{2}{*}{ Trap/kick } & Non-FMS & 3.4 & 1.6 & 70 & .640 \\
\hline & FMS & 3.5 & 2.0 & 107 & \\
\hline \multirow[t]{2}{*}{ Log roll } & Non-FMS & 2.5 & 1.6 & 70 & .182 \\
\hline & FMS & 3.0 & 1.6 & 107 & \\
\hline
\end{tabular}


Table 3: Mean and standard deviation of scores on each task divided by gender

\begin{tabular}{|c|c|c|c|c|c|}
\hline & Gender & Mean & SD & $\mathrm{N}$ & $\mathrm{p}$ \\
\hline Standing & Male & 10.7 & 2.8 & 89 & .235 \\
\hline broad jump & Female & 9.7 & 2.8 & 84 & \\
\hline Jump half & Male & 9.0 & 2.8 & 89 & .308 \\
\hline turn & Female & 9.8 & 2.3 & 84 & \\
\hline Over-arm & Male & 8.6 & 3.4 & 89 & $<.001$ \\
\hline throw & Female & 5.8 & 3. & 84 & \\
\hline \multirow[t]{2}{*}{ Kicking } & Male & 8.3 & 2.7 & 89 & .014 \\
\hline & Female & 6.3 & 2.8 & 84 & \\
\hline \multirow[t]{2}{*}{ Catch } & Male & 7.3 & 2.1 & 89 & .503 \\
\hline & Female & 7.1 & 2.2 & 84 & \\
\hline \multirow[t]{2}{*}{ Trapping } & Male & 5.9 & 2.2 & 89 & .016 \\
\hline & Female & 4.3 & 2.3 & 84 & \\
\hline Balance on & Male & 5.2 & 2.3 & 89 & .234 \\
\hline one foot & Female & 5.9 & 1.9 & 84 & \\
\hline Catch/thro & Male & 4.2 & 1.8 & 89 & .291 \\
\hline w & Female & 3.6 & 1.9 & 84 & \\
\hline \multirow[t]{2}{*}{ Trap/kick } & Male & 4.2 & 1.8 & 89 & $<.001$ \\
\hline & Female & 2.6 & 1.6 & 84 & \\
\hline \multirow[t]{2}{*}{ Log roll } & Male & 2.4 & 1.5 & 89 & .093 \\
\hline & Female & 3.2 & 1.6 & 84 & \\
\hline
\end{tabular}


Table 4: Correlations (and significance values) between motor tasks and selfperceptions

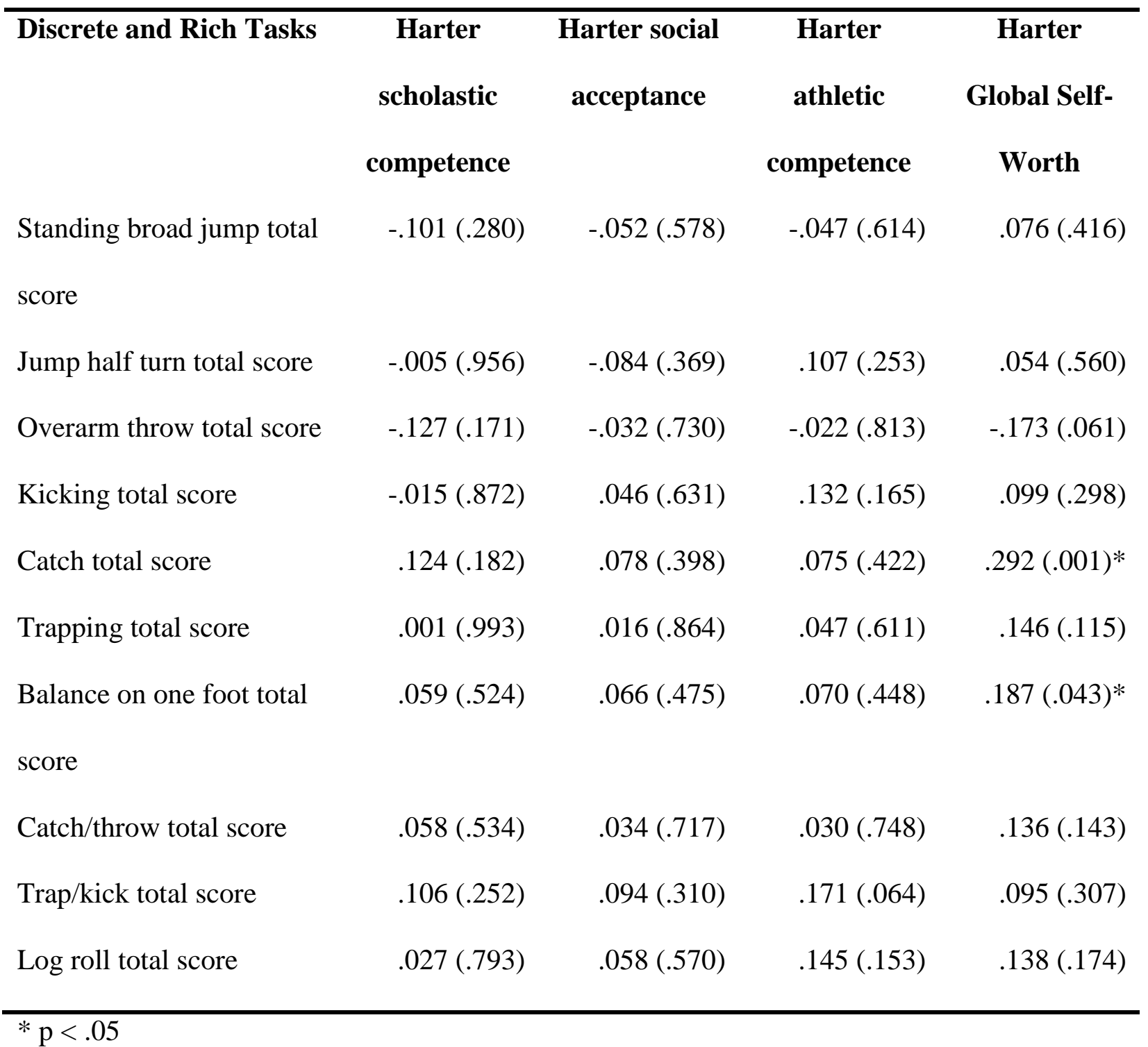


$\underline{\text { Table 5: Correlations (and significance values) between motor tasks, self-perceptions }}$ and SES

SES (based on \% of free school meals)

Standing broad jump total score

$.213(.005)^{*}$

Jump half turn total score

$.107(.170)$

Overarm throw total score

$.049(.524)$

Kicking total score

$.035(.658)$

Catch total score

$.063(.410)$

Trapping total score

$.133(.082)$

Balance on one foot total score

$-.103(.178)$

Catch/throw total score

$-.040(.607)$

Trap/kick total score

$.023(.768)$

Log roll total score

$-.279(<.001)^{*}$

Harter scholastic competence

$-.286(.002)^{*}$

Harter social acceptance

$-.218(.018)^{*}$

Harter athletic competence

$-.234(.011)^{*}$

Harter global self-worth

$-.147(.112)$

$* \mathrm{p}<.05$ 